\title{
Influência da adição de resíduo (lodo) de estação de tratamento de águas nas propriedades e microestrutura de cerâmica vermelha
}

\section{(Influence of the addition of water treatment sludge on the properties and microstructure of red ceramic)}

\author{
E. M. S. Oliveira ${ }^{1,2}$, J. N. F. Holanda ${ }^{1}$ \\ ${ }^{1}$ CCT-PPGECM, Universidade Estadual do Norte Fluminense, Av. Alberto Lamego 2000 \\ Campos dos Goytacazes, RJ 28013-602 \\ ${ }^{2}$ CEFET-Campos, Rua Dr. Siqueira 273, Campos dos Goytacazes, RJ 28030-130 \\ holanda@uenf.br
}

\begin{abstract}
Resumo
As estações de tratamento de águas (ETA) geram grandes quantidades de resíduo (lama). Este resíduo quando descartado nos sistemas hídricos provoca impacto ambiental negativo. No presente trabalho foi feito um estudo sobre a influência de um resíduo de estação de tratamento de águas nas propriedades e microestrutura de cerâmica vermelha. Foi preparada uma série de misturas argila/resíduo contendo até $15 \%$ em peso de resíduo de estação de tratamento de águas. Peças cerâmicas foram preparadas por prensagem uniaxial e sinterizadas entre 850 e $1050{ }^{\circ} \mathrm{C}$. As seguintes propriedades físico-mecânicas foram determinadas: retração linear, absorção de água, massa específica aparente e tensão de ruptura a flexão. A evolução da microestrutura e a análise de fases foram acompanhadas por microscopia eletrônica de varredura e difração de raios X. Os resultados experimentais mostraram que adição de até $15 \%$ em peso de resíduo de ETA não causa variações significativas na generalidade das propriedades tecnológicas da massa cerâmica padrão. A microestrutura das peças de cerâmica vermelha também não foi influenciada com a incorporação do resíduo estudado.
\end{abstract}

Palavras-chave: resíduo de ETA, cerâmica vermelha, microestrutura.

\begin{abstract}
The water treatment plants generate huge amounts of waste (water treatment sludge, WTS). This WTS as disposed in the hydric systems generates negative environmental impacts. In this work a study was done on the influence of a WTS in the properties and microstructure of red ceramic. A series of clay/waste mixtures were prepared with additions of up to 15 wt\% of WTS. Ceramic pieces were prepared by uniaxial pressing and firing between 850 and $1050{ }^{\circ} \mathrm{C}$. The following physical-mechanical properties were determined: linear shrinkage, water absorption, apparent density, and flexural strength. The microstructure and phase analysis evolution were accompanied by scanning electron microscopy and X-ray diffraction. The experimental results showed that the addition of up $15 \mathrm{wt} \%$ of WTS did not cause significant variations in the technological properties of the pure clayey body used as reference. The microstructure of the red ceramic pieces also was not influenced by the WTS added.
\end{abstract}

Keywords : WTS, red ceramic, microstructure.

\section{INTRODUÇÃO}

$\mathrm{Na}$ atualidade a necessidade premente de se preservar o meio ambiente tem chamado à atenção, nos meios acadêmico e industrial, para a valorização de processos que envolvam a reciclagem de resíduos poluentes. Isto decorre do fato de que o aproveitamento de resíduos contribui fortemente para a proteção ambiental e, conseqüentemente, para o desenvolvimento sustentado.

Um caso particular são as estações de tratamento de águas (ETAs) que geram enormes quantidades de resíduos (lodos). Nas ETAs a água bruta, que pode ser captada de mananciais superficiais e subterrâneos, é submetida a intenso processo de tratamento físico-químico [1-3]. Após tratamento, a água tratada deve apresentar qualidade satisfatória para consumo humano com padrão de água potável de acordo com a Organização Mundial de Saúde, que reúne as condições necessárias em termos de propriedades físicas, químicas e biológicas.

A forma mais comum de resíduo (lodo) de estação de tratamento de água é o produto da coagulação da água bruta, tendo uma composição aproximada daquela acrescido dos produtos resultantes do coagulante usado. Nas ETAs os coagulantes mais usados são [3]: sulfato de alumínio, sulfato férrico, sulfato ferroso, sulfato ferroso clorado, cloreto férrico, etc. De modo geral, as características dos resíduos (lodos) variam com a natureza da água bruta, dos processos unitários e produtos químicos aplicados. Considera-se, 
basicamente, como sendo constituídos de água e sólidos suspensos originalmente contidos na fonte de água, acrescidos de produtos resultantes dos reagentes aplicados à água nas etapas de tratamento.

O Brasil detém cerca de $12 \%$ das reservas de água doce do mundo [4], que corresponde a uma boa disponibilidade hídrica anual por habitante. Um país com dimensões continentais, com $8.514 .215,3 \mathrm{~km}^{2}$, composto por mais de 5.500 municípios e uma população atual da ordem 170.000.000 de habitantes demanda enormes volumes de água tratada para consumo humano. Uma conseqüência direta disso é a geração nas ETAs instaladas nos municípios espalhados por todo país de quantidades enormes de resíduos em forma de lama (lodo).

No Brasil, tradicionalmente, o destino dos resíduos (lodos) das estações de tratamento de águas tem sido, ao longo dos anos, os sistemas hídricos mais próximos. O aumento da consciência ambiental e as preocupações legítimas sobre a questão, envolveram uma nova sistematização para tentar mitigar tais impactos ambientais. Dentre os métodos alternativos de disposição de resíduos de ETAs (lodos) comumente usados estão incluídos [2]: lançamento nas redes coletoras, em lagoas com largo tempo de detenção, aplicação em aterro sanitário de lixo urbano, adubação e aproveitamento de subprodutos. Exceto o primeiro, os demais métodos exigem desidratação do lodo de modo a facilitar o manuseio e o transporte com a redução do volume. No entanto, tais procedimentos são, geralmente, atividades dispendiosas.

O resíduo de ETAs, quando, seco pode ser classificado como um resíduo sólido rico em argilominerais, silte e areia [5], com composição semelhante as das argilas comuns usadas em cerâmica vermelha. Do ponto de vista ambiental esse resíduo é classificado como sendo resíduo classe IIA - Não Inerte. Devido a este fato, este tipo de resíduo tem sido avaliado em vários trabalhos [6-9] como uma matériaprima alternativa para fabricação de produtos de cerâmica vermelha (tijolos, blocos cerâmicos e telhas). Em geral, ficou demonstrado que a cerâmica vermelha pode ser um destino final seguro para a reciclagem deste abundante resíduo. No entanto, ficou evidenciado também que a incorporação deste resíduo em cerâmica vermelha é mais complexa do que possa parecer. Isto decorre do fato de que os resíduos de ETAs apresentam características distintas, dependendo de sua origem e da época em que foi gerado.

Neste trabalho foi feito um estudo com o objetivo de avaliar a influência da incorporação de resíduo (lodo) de ETA proveniente da região de Campos dos Goytacazes, RJ, nas propriedades tecnológicas e microestrutura de cerâmica vermelha sinterizada.

\section{MATERIAIS E MÉTODOS}

Neste trabalho foram preparadas quatro massas cerâmicas contendo quantidades moderadas de até $15 \%$ em peso de resíduo de estação de tratamento de águas (Tabela I). Isto decorre do fato de que o resíduo de ETA utilizado apresenta
Tabela I - Composição das massas cerâmicas (\% em peso). [Table I - Composition of the ceramic pastes (wt \%).]

\begin{tabular}{ccc}
\hline Amostras & Massa Padrão & Resíduo de ETA \\
\hline E1 & 100 & 0 \\
E2 & 95 & 5 \\
E3 & 90 & 10 \\
E4 & 85 & 15 \\
\hline
\end{tabular}

alto valor de limite de plasticidade (água de plasticidade) da ordem de $53 \%$ muito acima da faixa recomendada para cerâmica vermelha [10]. Na preparação das massas de trabalho foi utilizada uma massa cerâmica argilosa industrial usada na fabricação de cerâmica vermelha na região de Campos dos Goytacazes-RJ, que corresponde à massa padrão. O resíduo foi coletado na ETA de Campos dos Goytacazes, RJ. A amostra do resíduo natural apresentou-se na forma de lama. Após secagem a $110{ }^{\circ} \mathrm{C}$ durante $24 \mathrm{~h}$, o resíduo seco foi destorroado e peneirado para a fração $<40$ mesh $(425 \mu \mathrm{m})$. De forma que daqui por diante o resíduo seco em forma de pó será denominado de resíduo de ETA. As matérias-primas foram misturadas e homogeneizadas num misturador cilíndrico durante 15 minutos. Em seguida, as massas cerâmicas foram umidificadas para $7 \%$ em peso de água.

A composição química das matérias-primas foi determinada por fluorescência de raios X. A análise mineralógica qualitativa das matérias-primas foi feita por difração de raios X em difratômetro Seifert modelo URD65, com radiação de $\mathrm{Cu}-\mathrm{K}_{\alpha}$, sob ângulo $2 \theta$ de $5^{\circ}$ até $60^{\circ}$. A granulometria das massas cerâmicas foi determinada por meio de uma combinação das técnicas de peneiramento e sedimentação de acordo com a norma NBR 7181-84 [11]. A plasticidade foi determinada de acordo com as normas NBR 6459-84 [12] e NBR 7180-84 [13].

As massas cerâmicas foram submetidas à compactação por prensagem uniaxial com ação única do pistão superior, utilizando-se uma matriz de aço de seção retangular (11,50 x 2,54) $\mathrm{cm}^{2}$. A pressão de compactação foi de $24 \mathrm{MPa}$. Após compactação, as peças cerâmicas foram submetidas a secagem em estufa a $110^{\circ} \mathrm{C}$ por $24 \mathrm{~h}$.

O processo de queima das peças cerâmicas foi realizado num forno elétrico tipo mufla. As temperaturas de patamar foram 850, 950 e $1050{ }^{\circ} \mathrm{C}$, que está dentro da faixa de temperatura de queima de fabricação industrial de cerâmica vermelha. Foi empregado um ciclo de queima lento (24 h frio a frio). Após queima, foram determinadas as seguintes propriedades físico-mecânicas: retração linear, absorção de água, massa específica aparente e tensão de ruptura à flexão.

A identificação das fases cristalinas nas peças cerâmicas após queima foi feita por difração de raios X. A microestrutura da superfície de fratura das amostras foi examinada via imagens de elétrons retro-espalhados (BSE), em um microscópio eletrônico de varredura Zeiss, modelo DSM 962 operando em $20 \mathrm{kV}$. 


\section{RESULTADOS E DISCUSSÃO}

Na Fig. 1 encontram-se os difratogramas de raios $\mathrm{X}$ do resíduo de ETA e da massa cerâmica padrão (amostra E1). O resíduo de ETA e a massa cerâmica argilosa são semelhantes do ponto de vista mineralógico. O resíduo é constituído, principalmente, de caulinita, sílica e gibsita, com indícios da presença da mica moscovita detectada por seus picos menos intensos. A massa cerâmica padrão é constituída por caulinita, sílica e gibsita, com indícios da presença de goetita, ilita/mica e feldspato potássico.

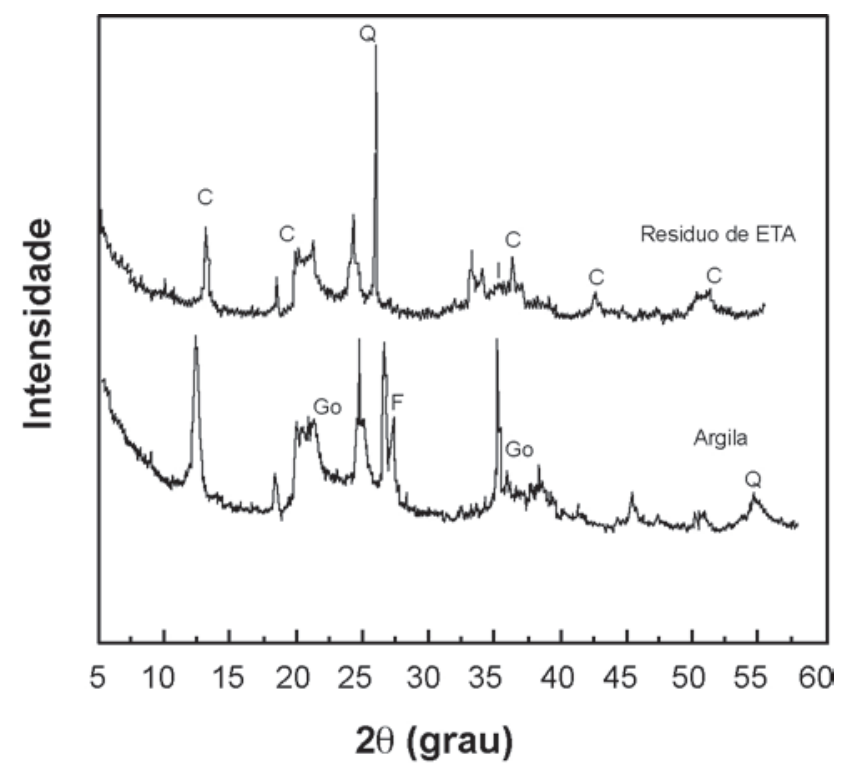

Figura 1: Difratogramas de raios X das matérias-primas utilizadas: C - caulinita; Q - quartzo; G - gibsita; I - ilita/mica; F - feldspato potássico.

[Figure 1: X-ray diffraction patterns of the raw materials used: $C$ - kaolinite; $Q$ - quartz; $G$ - gibbsite; I - illite/mica; $F$ - potash feldspar.]

As composições químicas do resíduo de ETA e da massa argilosa padrão estão apresentadas na Tabela II. Do ponto de vista químico, o resíduo e a massa cerâmica padrão são constituídos essencialmente por $\mathrm{SiO}_{2}, \mathrm{Al}_{2} \mathrm{O}_{3}$ e $\mathrm{Fe}_{2} \mathrm{O}_{3}$, que correspondema $80,42 \mathrm{e} 83,42 \%$, respectivamente. Noentanto, podem-se observar pequenas mas importantes diferenças na composição química destes materiais. A relação $\mathrm{SiO}_{2} / \mathrm{Al}_{2} \mathrm{O}_{3}$ para o resíduo é da ordem de 1,13 , enquanto que para a massa padrão é da ordem de 1,66. A relação $\mathrm{SiO}_{2} / \mathrm{Al}_{2} \mathrm{O}_{3}$ para a caulinita pura é de 1,18 . O resíduo de ETA contém menos óxidos fundentes $\left(\mathrm{K}_{2} \mathrm{O}+\mathrm{Na}_{2} \mathrm{O}+\mathrm{CaO}+\mathrm{MgO}\right)$, exceto óxido de ferro. Os dados da Tabela II ainda mostram que a perda ao fogo do resíduo de ETA é relativamente alta, 16,93\%, que está associada à desidroxilação da caulinita, desidratação da gibsita e decomposição de matéria orgânica [10].

Os dados granulométricos das massas cerâmicas preparadas são apresentados por faixa de tamanhos de interesse, conforme mostrado na Tabela III. Verifica-se que a incorporação de até 15\% em peso de resíduo de ETA
Tabela II - Composição química (\% em peso) das matériasprimas utilizadas.

[Table II - Chemical composition (wt. \%) of the raw materials used.]

\begin{tabular}{ccc}
\hline Compostos & Massa Padrão & Resíduo de ETA \\
\hline $\mathrm{SiO}_{2}$ & 46,42 & 35,92 \\
$\mathrm{Al}_{2} \mathrm{O}_{3}$ & 27,90 & 31,71 \\
$\mathrm{Fe}_{2} \mathrm{O}_{3}$ & 9,10 & 12,79 \\
$\mathrm{TiO}_{2}$ & 1,32 & 1,10 \\
$\mathrm{MnO}$ & 0,11 & 0,09 \\
$\mathrm{MgO}$ & 0,71 & 0,37 \\
$\mathrm{CaO}$ & 0,22 & 0,10 \\
$\mathrm{~K} 2$ & 1,67 & 0,58 \\
$\mathrm{Na}_{2} \mathrm{O}$ & 0,36 & 0,06 \\
$\mathrm{P}_{2} \mathrm{O}_{5}$ & 0,21 & 0,35 \\
Perda ao fogo & 11,96 & 16,93 \\
\hline
\end{tabular}

Tabela III - Distribuição de tamanho de partículas das massas cerâmicas (\%).

[Table III - Particle size distribution of ceramic pastes (\%).]

\begin{tabular}{cccc}
\hline Amostras & $\begin{array}{c}\text { Fração argila } \\
(<2 \mu \mathrm{m})\end{array}$ & $\begin{array}{c}\text { Silte } \\
(2 \leq \mathrm{x}<63 \mu \mathrm{m})\end{array}$ & $\begin{array}{c}\text { Areia } \\
(>63 \mu \mathrm{m})\end{array}$ \\
\hline E1 & 44 & 49 & 7 \\
E2 & 46 & 47 & 7 \\
E3 & 48 & 46 & 6 \\
E4 & 49 & 45 & 6 \\
\hline
\end{tabular}

resultou numa pequena modificação nas frações argila-silte. A fração argila tende a aumentar e a fração silte a diminuir com a incorporação do resíduo. As massas cerâmicas contêm alto conteúdo de partículas abaixo de $2 \mu \mathrm{m}$ (44-49\%). Esta fração está fundamentalmente associada à presença de argilominerais, particularmente a caulinita conforme mostrado na Fig. 1. O conteúdo da fração silte também variou na faixa (45-49\%).

A Fig. 2 mostra o índice de plasticidade de Atterbberg das massas cerâmicas estudadas. A plasticidade das massas está compreendida na faixa (27-29\%), que é adequada para fabricação de produtos de cerâmica vermelha [14]. A plasticidade aumentou à medida que se aumentou a quantidade de resíduo incorporado. A razão para isto pode estar relacionada ao aumento da quantidade de partículas com tamanho inferior a $2 \mu \mathrm{m}$ (fração argila). Além disso, é provável que a matéria orgânica, presente no resíduo, tenha contribuído, também, para aumentar a plasticidade das massas cerâmicas.

A Fig. 3 mostra os difratogramas de raios $X$ da amostra E1 (amostra de referência, $0 \%$ de resíduo de ETA) queimada entre $850{ }^{\circ} \mathrm{C}$ e $1050{ }^{\circ} \mathrm{C}$. Com base nos resultados da Fig. 1 e estudos prévios [15-17] foi possível identificar a série de transformações físico-químicas que ocorreram durante o 


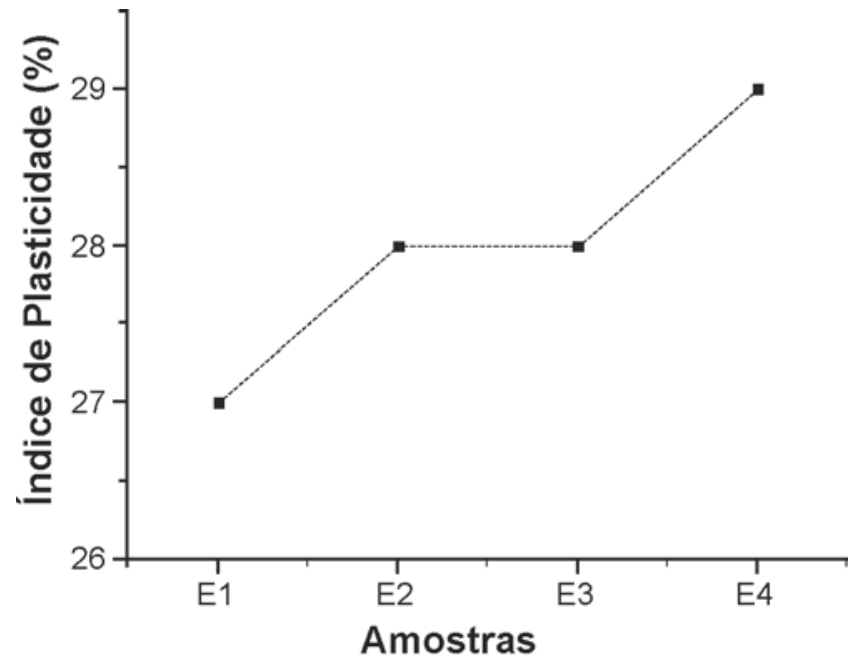

Figura 2: Plasticidade das massas cerâmicas. [Figure 2: Plasticity of the ceramic pastes.]

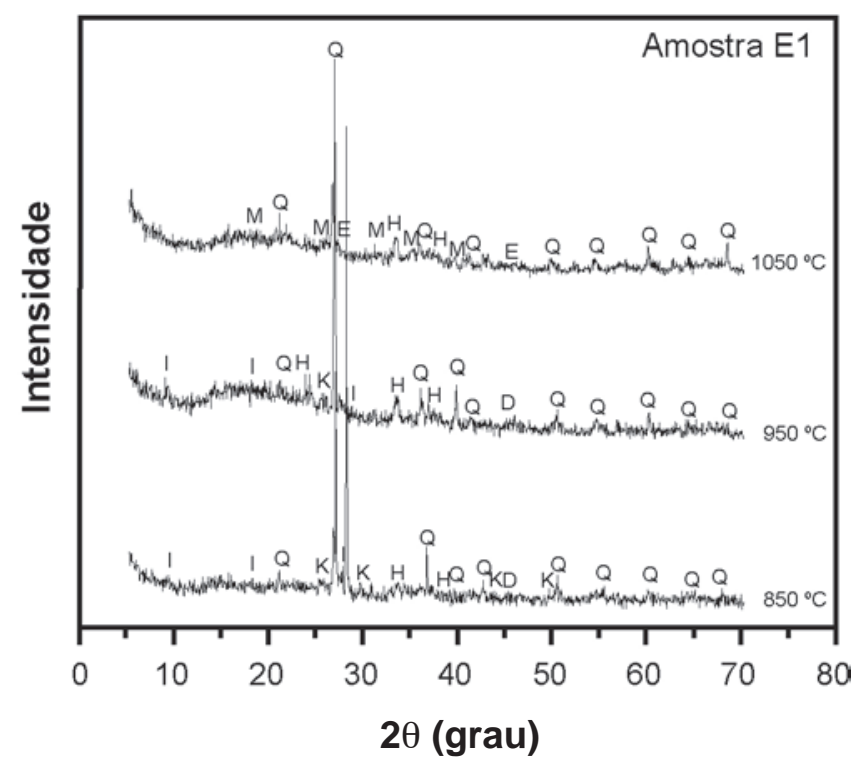

Figura 3: Difratogramas de raios $\mathrm{X}$ da amostra E1 a diferentes temperaturas: Q: quartzo; I: ilita/mica; K: feldspato potássico; H: hematita; D: $\delta-\mathrm{Al}_{2} \mathrm{O}_{3}$; $\mathrm{E}: \boldsymbol{\gamma}-\mathrm{Al}_{2} \mathrm{O}_{3}$; e M: mulita.

[Figure 3: X-ray diffraction patterns for the sample E1 at different temperatures: Q: quartz; I: illite/mica; K: potash feldspar; $H$ : hematite; $D$ : $\delta-\mathrm{Al}_{2} \mathrm{O}_{3}$; E: spinel $\left(\gamma-\mathrm{Al}_{2} \mathrm{O}_{3}\right)$; and $\mathrm{M}$ : mullite.]

processo de queima. Os resultados mostram que até $950{ }^{\circ} \mathrm{C}$ foram identificados picos característicos de quartzo, $\delta-\mathrm{Al}_{2} \mathrm{O}_{3}$, hematita, feldspato potássico e ilita/mica. A massa argilosa sob queima até $950^{\circ} \mathrm{C}$ teve importantes transformações tais como desidratação de hidróxidos, desidroxilação da caulinita para metacaulinita amorfa, decomposição de matéria orgânica e transformação do quartzo $\alpha-\beta$. Aumentando-se a temperatura até $1050{ }^{\circ} \mathrm{C}$ observou-se que ocorre o desaparecimento dos picos de ilita/mica e feldspato potássico. A hematita ainda está presente. Além disso, observou-se o aparecimento de picos da

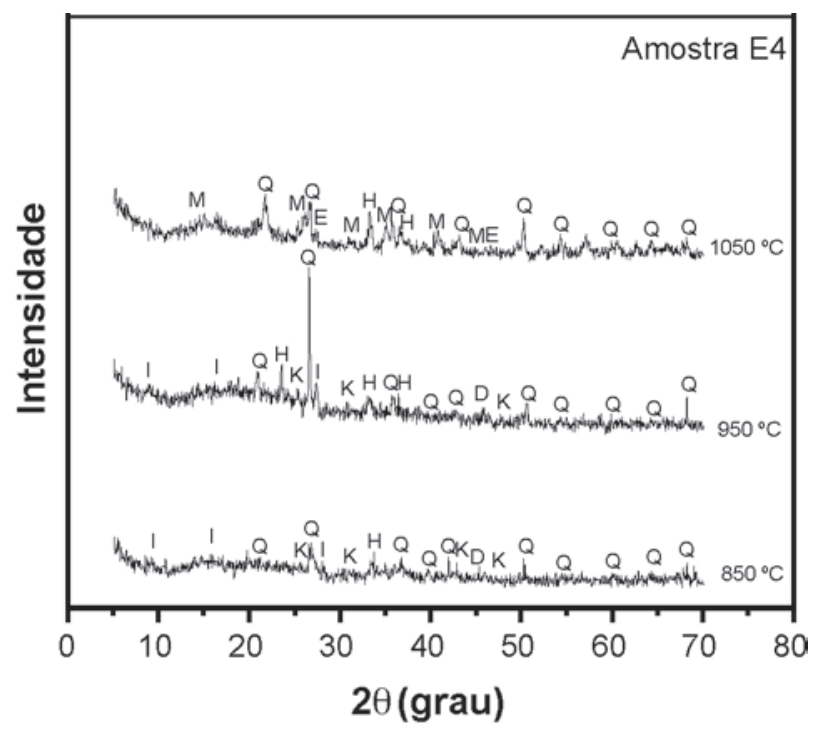

Figura 4: Difratogramas de raios $\mathrm{X}$ da amostra E4 a diferentes temperaturas: Q: quartzo; I: ilita/mica; K: feldspato potássico; $\mathrm{H}$ : hematita; D: $\delta-\mathrm{Al}_{2} \mathrm{O}_{3}$; $\mathrm{E}: \gamma-\mathrm{Al}_{2} \mathrm{O}_{3}$ ); e M: mulita.

[Figure 4: X-ray diffraction patterns for the sample E4 at different temperatures: Q: quartz; I: illite/mica; $K$ : potash feldspar; $H$ : hematite; $\mathrm{D}$ : $\delta-\mathrm{Al}_{2} \mathrm{O}_{3} ; \mathrm{E}$ : spinel $\left(\gamma-\mathrm{Al}_{2} \mathrm{O}_{3}\right)$; and M: mullite. ]

mulita derivada da reorganização estrutural da metacaulinita. Uma fase do tipo $\gamma-\mathrm{Al}_{2} \mathrm{O}_{3}$ também foi identificada. Picos de quartzo estão presentes após as temperaturas de queima. Contudo, as intensidades dos picos diminuíram principalmente em $1050{ }^{\circ} \mathrm{C}$. Isto pode estar relacionado à dissolução parcial das partículas de quartzo na fase vítrea, que provavelmente está em curso nesta temperatura. Na Fig. 4 estão mostrados os difratogramas de raios X para a amostra E4 (15\% em peso de resíduo de ETA) queimada entre 850 e $1050{ }^{\circ} \mathrm{C}$. Nota-se que as peças incorporadas com resíduo de ETA apresentaram uma composição de fase similar à amostra isenta de resíduo (Fig. 1). Assim, nenhuma nova fase cristalina resultante da interação entre o resíduo de ETA e a amostra de argila comum durante o processo de queima foi observada por difração de raios X.

Na Fig. 5, está mostrada a microestrutura da superfície de fratura da amostra E1 em diferentes temperaturas de queima. A $850{ }^{\circ} \mathrm{C}$ (Fig. 5a), a superfície de fratura se apresentou rugosa e a estrutura é notadamente porosa. Esta textura grosseira é resultado da fraca sinterização sólida entre as partículas de metacaulinita e minerais acessórios presentes. Além disso, deve ser considerado, também, o provável arrancamento de material durante a solicitação mecânica. A $950{ }^{\circ} \mathrm{C}$ (Fig. 5b) a superfície de fratura se apresentou com uma textura aparentemente mais suave, como resultado de um maior grau de sinterização da peça cerâmica. Em $1050^{\circ} \mathrm{C}$ (Fig. 5c) a superfície de fratura apresenta uma textura mais suave, correspondendo a uma microestrutura mais densa. Isto é decorrente do maior grau de sinterização e a presença de certo volume de fase vítrea na peça cerâmica nesta temperatura. Na Fig. 6 está mostrada a microestrutura da superfície de fratura da amostra E4 (15\% em peso de resíduo 

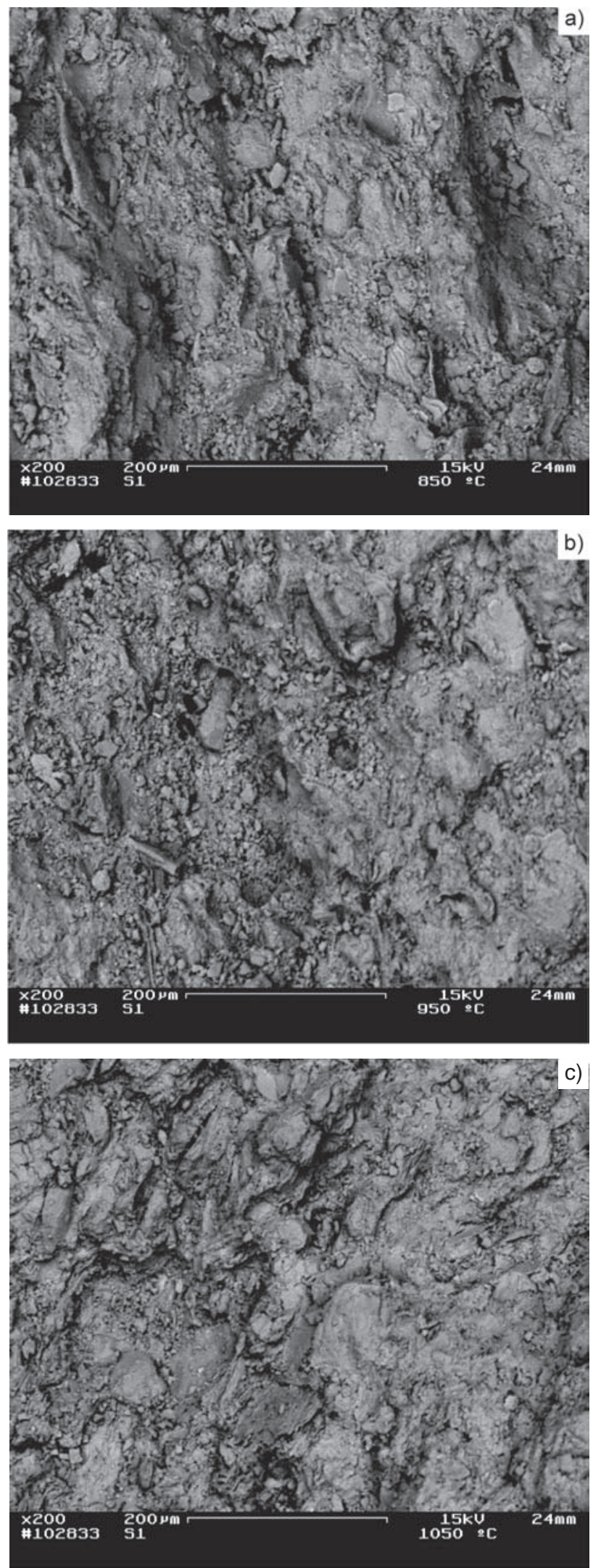

Figura 5: Micrografias obtidas por MEV/BSE da amostra E1: (a) $850{ }^{\circ} \mathrm{C}$; (b) $950{ }^{\circ} \mathrm{C}$; e (c) $1050{ }^{\circ} \mathrm{C}$.

[Figure 5: SEM/BSE micrographs for the sample E1: (a) $850{ }^{\circ} \mathrm{C}$; (b) $950{ }^{\circ} \mathrm{C}$; and (c) $\left.1050{ }^{\circ} \mathrm{C}.\right]$
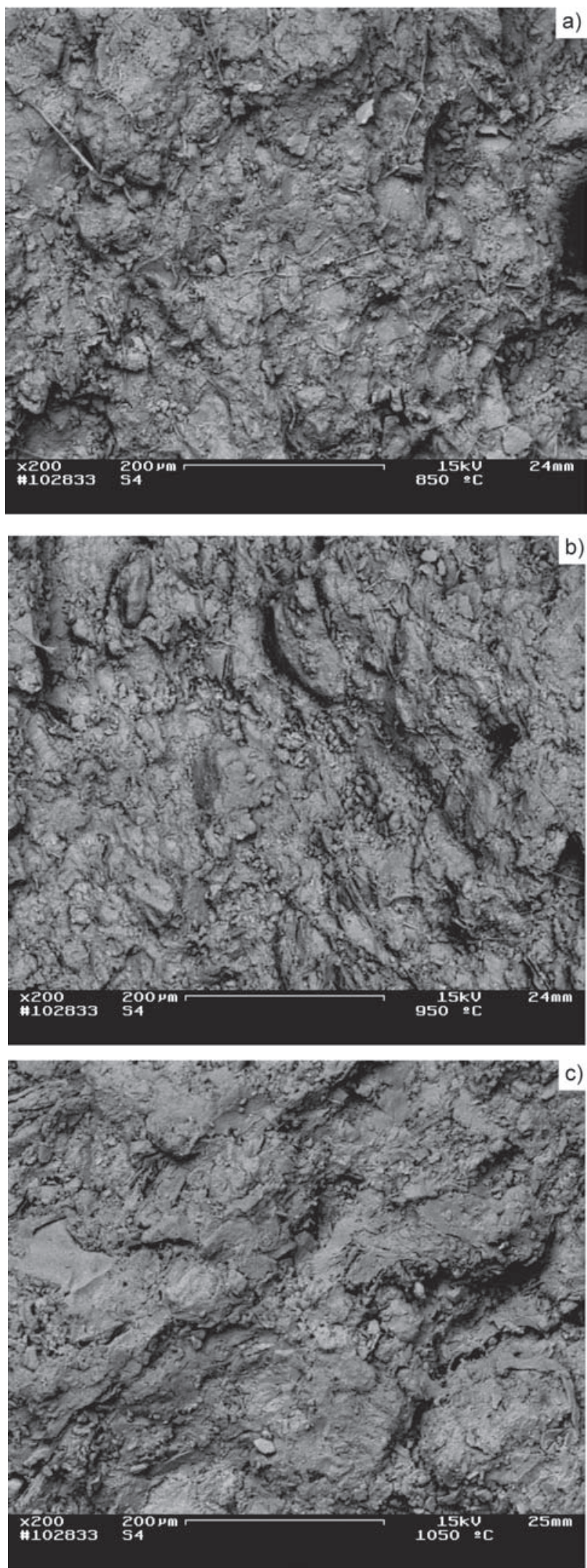

Figura 6: Micrografias obtidas por MEV/BSE da amostra E4: (a) $850{ }^{\circ} \mathrm{C}$; (b) $950{ }^{\circ} \mathrm{C}$; e (c) $1050{ }^{\circ} \mathrm{C}$.

[Figure 6: SEM/BSE micrographs for the sample E4: (a) $850{ }^{\circ} \mathrm{C}$; (b) $950{ }^{\circ} \mathrm{C}$; and (c) $1050{ }^{\circ} \mathrm{C}$.] 


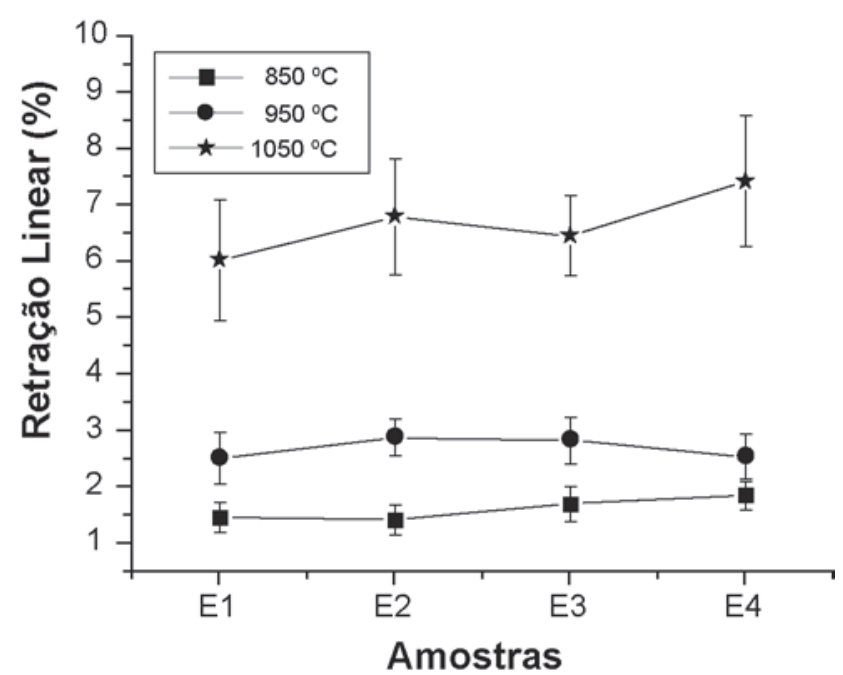

Figura 7: Retração linear em função do percentual de resíduo de ETA e da temperatura de queima.

[Figure 7: Linear shrinkage as a function of WTS percent for all firing temperatures.]

de ETA) em diferentes temperaturas de queima. As peças contendo resíduo de ETA apresentaram uma microestrutura muito similar àquela da amostra de referência (Fig. 5).

Os resultados das propriedades físico-mecânicas das peças cerâmicas queimadas em diferentes temperaturas estão mostrados nas Figs. 7-10. Na Fig. 7 está mostrado o comportamento da retração linear das peças cerâmicas em função do conteúdo do resíduo de ETA. A retração linear experimenta somente pequenas alterações, mesmo assim dentro da dispersão (valores de desvio padrão) encontrada. Este comportamento foi observado para todas as temperaturas de queima estudadas. Na Fig. 7 observa-se também que a retração linear aumentou com o aumento da temperatura de queima, como resultado do aumento do grau de sinterização das massas cerâmicas. A $1050{ }^{\circ} \mathrm{C}$ ocorreu um forte aumento dos valores de retração linear $(6,03-7,44 \%)$ para todas as massas estudadas. Este comportamento está associado, principalmente, ao processo de vitrificação dos corpos cerâmicos que está em curso nesta temperatura.

Na Fig. 8 está mostrada a curva resultante dos valores de absorção de água como função do conteúdo de resíduo de ETA. A absorção de água, praticamente, não se alterou com o aumento do conteúdo de resíduo de ETA. Já o efeito da temperatura de queima foi significativo somente a $1050{ }^{\circ} \mathrm{C}$. Nesta temperatura, a absorção de água foi diminuída devido à permeação do líquido vítreo formado ao longo da porosidade aberta do corpo cerâmico. O comportamento da absorção de água seguiu, aproximadamente, os observados para a retração linear (Fig. 7) e para a massa específica aparente (Fig. 9).

Na Fig. 9 estão os resultados de massa específica aparente em função do conteúdo de resíduo de ETA. A incorporação de até $15 \%$ em peso de resíduo de ETA não acarretou modificações significativas no comportamento de densificação dos corpos cerâmicos.

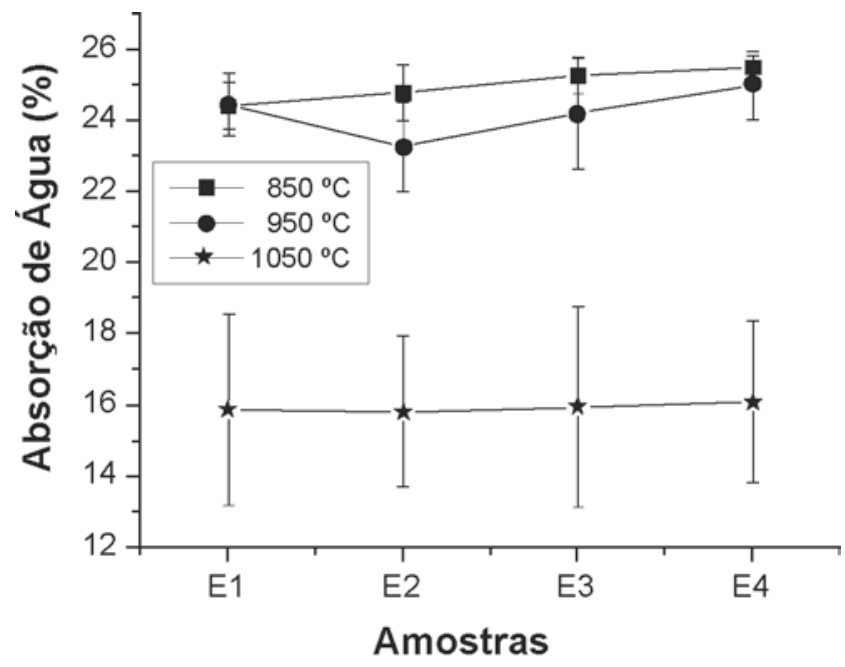

Figura 8: Absorção de água em função do percentual de resíduo de ETA e da temperatura de queima.

[Figure 8: Water absorption as a function of WTS percent for all firing temperatures.]

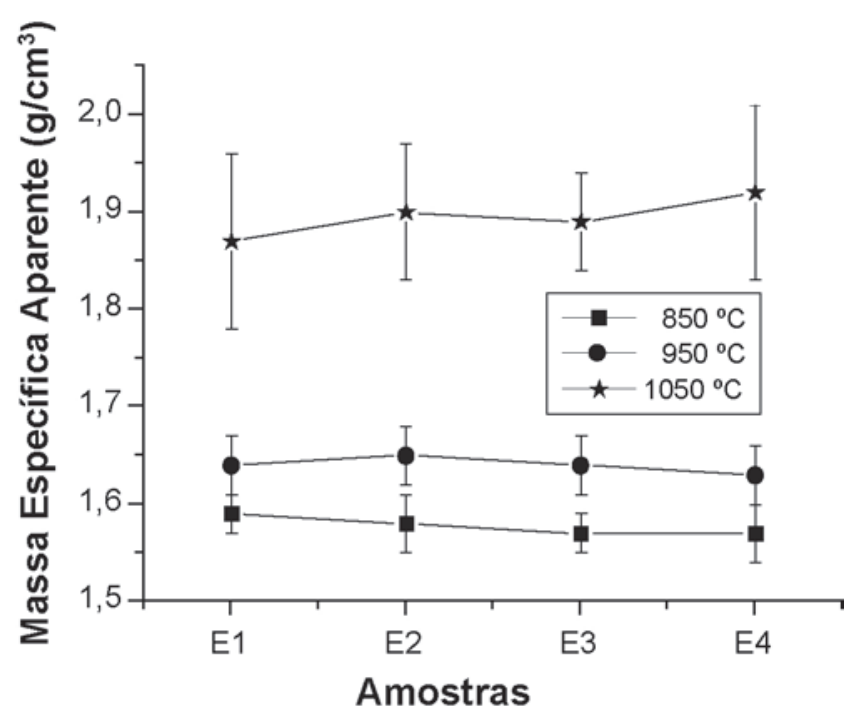

Figura 9: Massa específica aparente em função do percentual de resíduo de ETA e da temperatura de queima.

[Figure 9: Apparent specific mass as a function of WTS percent for all firing temperatures.]

Na Fig. 10 é mostrado o comportamento da tensão de ruptura à flexão dos corpos cerâmicos. A tensão de ruptura não apresenta grandes alterações com a incorporação do resíduo para todas as temperaturas estudadas. Além disso, o comportamento desta propriedade mecânica foi similar ao observado para as demais propriedades físicas, cujas flutuações estão dentro das dispersões encontradas. Observou-se, também, que a tensão de ruptura aumentou com o aumento da temperatura de queima, como resultado da redução da porosidade aberta no interior do corpo cerâmico. 


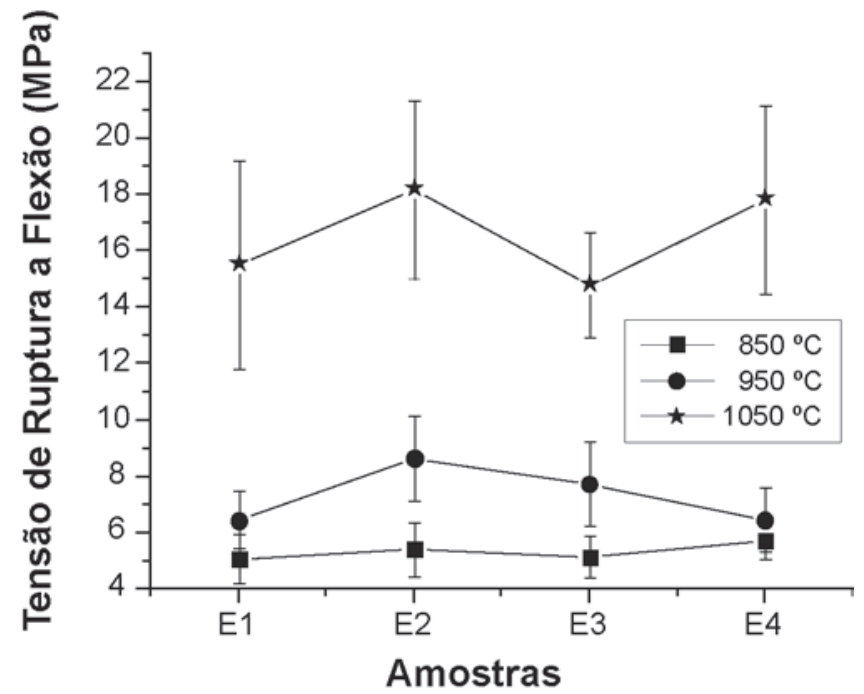

Figura 10: Tensão de ruptura à flexão em função do percentual de resíduo de ETA e da temperatura de queima.

[Figure 10: Flexural strength as a function of WTS percent for all firing temperatures.]

A alta densificação em $1050{ }^{\circ} \mathrm{C}$ foi responsável pelos altos valores de resistência mecânica (14,78-18,18 MPa).

\section{CONCLUSÕES}

O resíduo de ETA pode ser incorporado como matériaprima alternativa na formulação de massa argilosa para a fabricação de cerâmica vermelha. O resíduo de ETA estudado, quando adicionado em quantidades de até 15\% em peso a uma massa argilosa industrial para fabricação de cerâmica vermelha não apresentou efeitos significativos sobre a microestrutura e as propriedades físico-mecânicas avaliadas (retração linear, absorção de água, massa específica aparente e tensão de ruptura à flexão). O efeito da temperatura de queima foi o de aumentar o grau de sinterização das massas cerâmicas, sobretudo acima de $950^{\circ} \mathrm{C}$, com influência marcante sobre a microestrutura e propriedades estudadas.

\section{AGRADECIMENTOS}

Ao CNPq pelo apoio financeiro e ao Consórcio Águas do Paraíba pelo fornecimento do resíduo de ETA. Os autores agradecem, também, ao Dr. Claudinei dos Santos (EEL/ USP) pelo suporte na análise por difração de raios X.

\section{REFERÊNCIAS}

[1] M. J. Hammer, Sistemas de abastecimento de águas e esgotos, Editora Livros Técnicos e Científicos, Rio de Janeiro (2000) 563p.

[2] C. A. Richter, Tratamento de lodos de estações de tratamento de águas, Editora Edgard Blücher, S. Paulo (2001) 102p.

[3] http://www.tratamentodeagua.com.br, acessado em $16 / 03 / 2004$.

[4] P. C. Magalhães, Ciência Hoje 35, 211 (2004) 45-49.

[5] E. M. S. Oliveira, S. Q. Machado, J. N. F. Holanda, Cerâmica 50, 316 (2004) 324-330.

[6] I. S. S. Santos, M. V. V. Ramires, C. S. Kazmierczak, H. C. Silva, A. P. Kern, S. A. Camargo, Anais do $45^{\circ}$ Congresso Brasileiro de Cerâmica, Florianópolis, SC (2001) cd rom, p. 201-214.

[7] C. G. Mothé, A. Câmara, H. F. Mothé Filho, Anais do 48 Congresso Brasileiro de Cerâmica, Curitiba, PR (2004) cd rom.

[8] E. M. S. Oliveira, V. G. Sampaio, J. N. F. Holanda, Ind. Ceram. 26, 1 (2006) 23-28.

[9] S. R. Teixeira, S. A. Souza, N. R. Souza, P. Aléssio, G. T. A. Santos, Cerâmica 52, 323 (2006) 215-220.

[10] E. M. S. Oliveira, Tese de Doutorado, Universidade Estadual do Norte Fluminense, PPGECM-CCT, Campos dos Goytacazes, RJ (2004).

[11] ABNT, NBR 7181-84, Solo: Análise granulométrica, Rio de Janeiro, (1984).

[12] ABNT, NBR 6459-84, Solo: Determinação do limite de liquidez, Rio de Janeiro (1984).

[13] ABNT, NBR 7180-84, Solo: Determinação do limite de plasticidade, Rio de Janeiro (1984).

[14] M. Dondi, Int. Ceram. J. (2003) 55-59.

[15] P. S. Santos, Ciência e Tecnologia de Argilas, vol. 1, 2 ${ }^{\mathrm{a}}$ Ed., Edgard Blücher Ltda., S. Paulo (1989).

[16] G. P. Souza, R. Sánchez, J. N. F. Holanda, J. Therm. Anal. Calor. 73, 1 (2003) 293-305.

[17] A. Aras, Appl. Clay Sci. 24 (2004) 257-269.

(Rec. 23/07/2007, Rev. 25/11/2007, Ac. 14/12/2007) 